\title{
Synthesis, characterization, and biocompatible properties of alanine- grafted chitosan copolymers
}

\author{
Gyu Han Park ${ }^{1}$, Min-Sil Kang ${ }^{1}$, Jonathan C Knowles ${ }^{1,2}$, Myoung-Seon Gong ${ }^{1}$ \\ ${ }^{I}$ Department of Nanobiomedical Science, Dankook University Graduate School, Cheonan,
} Chungnam 330-714, Korea

${ }^{2}$ Division of Biomaterials and Tissue Engineering, UCL Eastman Dental Institute, University College London, London, UK

\begin{abstract}
In order to overcome major problems regarding the lack of affinity to solvents and limited reactivity of the free amines of chitosan, introduction of appropriate spacer arms having terminal amine function is considered of interest. $L$-Alanine- $N$-carboxyanhydride (Ala-NCA) was grafted onto chitosan via anionic ring-opening polymerization. The chemical and structural characterizations of $L$-alanine-grafted chitosan (Ala-g-Cts) were confirmed through Fourier transform infrared spectroscopy (FTIR) and proton nuclear magnetic resonance spectroscopy $\left({ }^{1} \mathrm{H}\right.$ NMR). In addition, the viscoelastic properties of Ala-g-Cts were examined by means of a rotational viscometer, and thermal analysis was carried out with a thermogravimetric analyzer (TGA) and differential scanning calorimetry (DSC). Morphological changes in the chitosan $L$-alanine moiety were determined by x-ray diffraction. To determine the feasibility of using these films as biomedical materials, we investigated the effects of their $L$-alanine content on physical and mechanical properties. The biodegradation results of crosslinked Ala-g-Cts films were evaluated in phosphate buffered solution (PBS) containing lysozyme at $37^{\circ} \mathrm{C}$. Proliferation of MC3T3-E1 cells on crosslinked Ala-g-Cts films was also investigated with use of the CCK-8 assay.
\end{abstract}


Keywords: chitosan; $L$-alanine-NCA; graft polymer; biocompatibility; MC3T3-E1 cells Corresponding Author, Email: msgong@dankook.ac.kr 


\section{Introduction}

Chitosan is a nontoxic, ${ }^{1}$ biodegradable, ${ }^{2,3}$ and biocompatible ${ }^{4,5}$ natural polymer made up of randomly distributed $\mathrm{N}$-acetyl glucosamine and glucosamine units. Typically, chitosan is obtained through deacetylation of the $N$-acetyl glucosamine units of chitin, generally by alkaline hydrolysis, but the deacetylation of chitin is rarely complete. When the degree of acetylation falls below the value of $60 \mathrm{~mol} \%$, chitin becomes chitosan. Chitosan offers remarkable biological properties that have paved the way for its application in the pharmaceutical and biomedical fields, ${ }^{6,7}$ in new drug delivery systems ${ }^{8,9,10}$ or as a scaffold for tissue engineering. ${ }^{11}$ Indeed, chitosan has good mucoadhesive properties owing to its positive charge, ${ }^{12}$ which increases adhesion to mucosa and therefore the duration of contact for drug penetration. Its hemostatic properties make chitosan a good candidate for wound dressing, ${ }^{13,14}$ and its antibacterial property limits the risk of infection. ${ }^{15,16}$

These potential applications of chitosan make it necessary to establish efficient, appropriate modifications to explore fully the possibility of more diverse uses. Chitosan is not soluble in pure water or organic solvents but is soluble in aqueous solutions of organic or mineral acids under specific conditions. Chitosan is a weak base with a $\mathrm{p} K$ a value of the $D$ glucosamine residue of about 6.2 to 7.0. Its insolubility in aqueous solutions at $\mathrm{pH}>6.0$ limits some of chitosan's potential applications. ${ }^{1,8}$ Several approaches have been attempted to modify its hydrophilic groups. The most common of which are quaternization of the amino groups and the grafting of polymers. ${ }^{17-20}$ However, grafted chitosan has comparatively poor solubility in most of the common organic solvents, thus limiting its applications; its poor solubility in water also poses a serious disadvantage to its practical use. Many attempts have been made to increase the solubility of chitosan. ${ }^{21,22}$ In general, the organic solvents used to modify chitosan include pyridine, tetrahydrofuran (THF), dimethylformamide (DMF), and 
dimethyl sulfoxide (DMSO), but chitosan has also been combined with water to aid in its solubilization. ${ }^{23}$ In order to overcome major problems regarding to the lack of affinity to solvents and limited reactivity of the free amines in the chitosan, introduction of appropriate spacer arms with terminal amine group is considered of interest. Herein, we report the modification of chitosan with $L$-alanine- $N$-carboxyanhydride as a grafting monomer to strengthen the hydrophilicity of the chitosan, which retains the primary amine covalently bonded at one of its ends. The resulting Ala-g-Cts copolymers have been characterized by infrared and nuclear magnetic resonance (NMR) spectroscopic techniques to elucidate their detailed structure. The physical properties of Ala-g-Cts were determined by differential scanning calorimetry (DSC) and thermogravimetric analysis (TGA), and the rheology, morphology, and mechanical properties were estimated by viscometry, x-ray diffraction, scanning electron microscopy, and tensile testing. To assess the feasibility of using Ala-g-Cts copolymers as a biocompatible material, we also studied their biodegradation and cell and tissue compatibility after proliferation of MC3T3-E1 cells of the Ala-g-Cts system.

\section{Materials and Methods}

\section{Materials}

Chitosan (Cts, $\mathrm{Mw}=100-300 \mathrm{kDa}$; degree of acetylation=79.58\%) was purchased from Sigma-Aldrich Chem. Co. Ltd. Viscosity determined by Brookfield was $800-2000 \mathrm{cP}$ at $25{ }^{\circ} \mathrm{C}$ using $1 \mathrm{wt} \%$ in $1 \%$ acetic acid. Tetrahydrofuran (THF), $n$-hexane, $N, N$-dimethylformamide (DMF) were purchased from Duksan Pure Chem. Co., Ltd. THF were distilled over freshly powdered calcium hydride $\left(\mathrm{CaH}_{2}\right)$ and were distilled under ambient pressure. DMF was dried with $\mathrm{CaH}_{2}$ and was distilled under reduced pressure, and stored with molecular sieves. $L$ alanine- $N$-carboxyanhydride (Ala-NCA) was prepared by reacting $L$-alanine with 
triphosgene. ${ }^{24-27}$ The Ala-NCA was recrystallized twice, dried under vacuum and stored in a refrigerator under $\mathrm{P}_{2} \mathrm{O}_{5}$. Glutaraldehyde solution $\left(50 \%\right.$ in $\left.\mathrm{H}_{2} \mathrm{O}\right)$ supplied by Sigma-Aldrich were used without further treatment. All other reagents were of analytical grade and were used directly without further purification.

\section{Instruments}

Fourier transform infrared (FT-IR) spectra were collected with a Varian 6000 FT-IR spectrometer and all samples were prepared as $\mathrm{KBr}$ pellets at room temperature. ${ }^{1} \mathrm{H}$ NMR spectra for the synthesized Ala-g-Cts were recorded with a Bruker Avance 400 spectrometer (400 MHz, Karlsruhe, Getmany) and performed at ambient temperature with 5\% (w/v) polymer solution in $\mathrm{D}_{2} \mathrm{O}$. The ${ }^{1} \mathrm{H}$ NMR spectra were recorded on a Bruker Avance 400 spectrometer (400 MHz, Karlsruhe, Getmany). All measurements were performed at $25{ }^{\circ} \mathrm{C}$, using the pulse accumulation of 64 scans and LB parameter of $0.30 \mathrm{~Hz}$. CHN elemental composition was determined using a Perkin Elmer Elemental Analyzer (Model 2400).

Crystalline characteristics were analyzed by a Rigaku Ultima IV powder X-ray diffraction (XRD) using a $\mathrm{CuK}_{\alpha}$ radiation at $1.5405 \AA$. Scan parameters were set at $5 \mathrm{~s}$ scan speed and increment at 0.02 . Thermal behaviors were investigated using differential scanning calorimetry (DSC, Mettler Toledo DSC 823e/400, USA). The powder of $10 \mathrm{mg}$ sample was heated up at the rate of $5{ }^{\circ} \mathrm{C} / \mathrm{min}$ from $25{ }^{\circ} \mathrm{C}$ to $400{ }^{\circ} \mathrm{C}$, respectively. In this work, the apparent rheological behavior and gelation of the Ala-g-Cts solution was measured by a rotational viscometer HAAKE 550 (Thermo Scientific, Germany), with a coaxial cylinder sensor $\mathrm{SV}_{1}$, at controlled constant temperature $25{ }^{\circ} \mathrm{C}$. The thermosatatic double-walled $\mathrm{NV}_{1}$ rotor was housed in a $12 \mathrm{~mL}$ cup filled with the solution under study and the measurements were done at the shear rate value from near 0 to $200^{-1} \mathrm{~s}$ that did not generate excessive 
mechanical degradation of the polymers. The survey was carried out three times with samples at $25{ }^{\circ} \mathrm{C}$ and $37^{\circ} \mathrm{C}$, the shearing time was $200 \mathrm{~s}$, sample solutions were kept at room temperature in glass bottles in a dark place until analysis. All the determinations were done in quadruplicate.

\section{Preparation of alanine-grafted chitosan (Ala-g-Cts) copolymer}

Chitosan (Cts) $\left(8 \mathrm{~g}, 4.69 \times 10^{-2} \mathrm{~mol}\right)$ was swelled in dry DMF $(100 \mathrm{~mL})$ at room temperature for $5 \mathrm{~h}$ in a round-bottomed flask $(500 \mathrm{~mL})$ equipped with a dropping funnel, a mechanical stirrer, and a nitrogen-inlet system. The solution of Ala-NCA $\left(5.398 \mathrm{~g}, 4.69 \times 10^{-2} \mathrm{~mol}\right)$ dissolved in DMF (100 $\mathrm{mL})$ was added to the Cts suspension in DMF solution. Polymerization of Ala-NCA was carried out at $70{ }^{\circ} \mathrm{C}$ with vigorous stirring under dry nitrogen for 3 days. The supernatant was re-precipitated in a cool acetone, and the precipitate was filtered and washed repeatedly in acetone. The final solid product was dried under reduced pressure overnight to produce a fine, light-yellow powder. The reaction yields of Ala-g-Cts1, Ala-g-Cts3, and Ala-g-Cts5 were 89.5, 87.2 and $86.3 \%$, respectively. The Ala-gCts copolymers were designated Ala-g-Cts1, Ala-g-Cts3, and Ala-g-Cts5, with the number 1 referring to the molar ratio of Ala-NCA to amine function in Cts.

\section{Preparation of Ala-g-Cts films}

In a typical experiment, the crosslinked Ala-g-Cts films were prepared using the solvent evaporation casting technique. Ala-g-Cts sample (10 g) was crosslinked in $100 \mathrm{~mL}$ of a $0.5 \%$ (w/w) glutaldehyde solution in phosphate buffer $\left(0.054 \mathrm{M} \mathrm{Na}_{2} \mathrm{HPO}_{4}, 0.013 \mathrm{M} \mathrm{NaH}_{2} \mathrm{PO}_{4}, \mathrm{pH}\right.$ 7.4). After the Ala-g-Cts solution had been mixed with glutaldehde solution, the mixed solution was kept under reduced pressure to get rid of air bubbles. The solution was cast on a 
glass plate at room temperature for 2, and a gel-like sheet with a thickness of about $0.2 \mathrm{~mm}$ was prepared. After crosslinking, the Ala-g-Cts samples were rinsed for 30 min by running tap water, washed twice with $4 \mathrm{M} \mathrm{NaCl}$ and washed four times with distilled water to hydrolyse any Schiff base and remove unreacted glutaldehyde before lyophilization. The glutaldehyde concentration in the washing water of the final washing step was less than 0.2 ppm as determined with the glutaldehyde assay. The crosslinked Ala-g-Cts3 and Ala-g-Cts5 films containing more $L$-alanine were prepared using procedures similar to those described above.

\section{Solubility of Ala-g-Cts}

We tested the solubility of Ala-g-Cts in several organic solvents as well as in deionized water. The samples were soaked in each solvent at a concentration of $10 \mathrm{mg} / \mathrm{mL}$. More detailed extent of the solubility of Ala-g-Cts copolymers in phosphate buffered solution and organic solvent was measured as follows: Film portions measuring $1 \mathrm{~cm}^{2}$ were placed in a test tube with phosphate buffered solution $(0.1 \mathrm{M}, 20 \mathrm{~mL})$ and shaken gently at $37{ }^{\circ} \mathrm{C}$ for $24 \mathrm{~h}$. The solution was then filtered through Whatman (No. 1) filter paper to recover the remaining undissolved film, which was desiccated at $70{ }^{\circ} \mathrm{C}$ for $24 \mathrm{~h}$. The solubility of the film (FS) was calculated using the equation FS $(\%)=\left(\left(\mathrm{W}_{i}-\mathrm{W}_{r}\right) / \mathrm{W}_{i}\right) \times 100$, where $\mathrm{W}_{i}$ was the initial weight of the film expressed as dry matter and $\mathrm{W}_{r}$ was the weight of the undissolved desiccated film residue. All determinations were carried out by the same method in three separate test runs in organic solvent.

Swelling behavior of crosslinked Ala-g-Cts 
The swelling behavior of the crosslinked Ala-g-Cts films was measured by allowing the film to swell in pH 7.0 phosphate buffered solution. Each film was divided into circle-shaped portions and weighed. These Ala-g-Cts films were immersed in solutions of $\mathrm{pH} 7.0$ and kept at $37^{\circ} \mathrm{C}$, with immersion times ranging from 2 to $24 \mathrm{~h}$. The films were withdrawn from the solution at different time intervals, and their wet weight was determined immediately after first being blotted with filter paper to remove surface water. The degree of swelling for each sample at a specific time was calculated according to the following relationship: degree of swelling $=\left(\mathrm{W}_{t}-\mathrm{W}_{d}\right) / \mathrm{W}_{d}$, where $\mathrm{W}_{t}$ and $\mathrm{W}_{d}$ are the weights of the samples at time $\mathrm{T}$ and in the dry state, respectively.

\section{Enzymatic degradation of crosslinked Ala-g-Cts}

The in vitro degradation of the Ala-g-Cts film was followed in $0.01 \mathrm{M}$ phosphate buffered solution $(\mathrm{pH}=7.4,10 \mathrm{~mL})$ at $37^{\circ} \mathrm{C}$ containing $1 \mathrm{mg} / \mathrm{mL}$ lysozyme (hen egg white, SigmaAldrich Chem. Co.) and samples were each 10 20 mg in weight. Then film samples were shaken to do the degradation at regular intervals time course weight-change experiment of enzymatic degradation. The films samples were removed from the medium, washed with distilled water, freeze-dried and weighed. The extent of in vitro degradation was expressed as the percentage of the weight of the dried film and the weight loss ratio was defined as $100 \%$ $\mathrm{x}\left(\mathrm{W}_{0}-\mathrm{W}_{t}\right) / \mathrm{W}_{0} . \mathrm{W}_{0}$ and $\mathrm{W}_{t}$ are the weights of the film sample and the weight loss of the enzymatic degradation of film sample as a function of time, respectively.

\section{Cytotoxicity assay}

Proliferation assays evaluate cell reaction to matrix, medium, and conditions. In this study, we specifically focus on the measurements of cell proliferation of MC3T3-E1 cell in Ala-g- 
Cts film for biomaterial application. Cell Proliferation Kit (CCK-8; Dojindo Laboratories, Kumamoto, Japan) 2-(methoxy-4-nitrophenyl)-3-(4-nitrophenyl)-5-(2,4-disulfophenyl)-2Htetrazolium, monosodium salt was used according to the manufacturer's recommendation. MC3T3-E1 murine calvarial osteoblasts cells were cultured in $\alpha$-MEM (Invitrogen, Paisley, UK) supplemented with 10\% fetal bovine serum (FBS: Gibco, Daejeon, South Korea), 100 $\mathrm{pg} / \mathrm{mL}$ penicillin and streptomycin (Gibco, Daejeon, South Korea) at $37{ }^{\circ} \mathrm{C}$ in a humidified atmosphere of $5 \% \mathrm{CO}_{2}$ and the medium was changed every 2 days until the end of the experiment. Prior to cell seeding, Ala-g-Cts films were removed and cells were washed with PBS three times and sterilized overnight with ultraviolet radiation. Subsequently, $200 \mu \mathrm{L}$ of previously cultured MC3T3-E1 osteoblasts cell suspension was added to each Ala-g-Cts film in a 48 well plate and cultured in an incubator at $37{ }^{\circ} \mathrm{C}$ with $5 \% \mathrm{CO}_{2}$ for $1,3,5$ and 7 days. At each time point, the extraction medium was aspirated and CCK- 8 proliferation kit reagents were added to cells and the optical density (OD) of live cells was measured using a microplate reader at a wavelength of $450 \mathrm{~nm}$. All the procedures were replicated 3 times.

\section{Results and Discussion}

\section{Preparation of Ala-g-Cts}

The Ala-g-Cts copolymer was prepared by reacting Ala-NCA with Cts, as shown in Figure 1. Polymerization of Ala-NCA can occur via two different mechanisms, their relative contributions being determined by the relative nucleophilicity and basicity of the bases. In the amine mechanism in this study, the nucleophilic attack monomer at the C5 position resulted in ring opening through scission of the acyl-oxygen bond. The resultant carbamate eliminates $\mathrm{CO}_{2}$ following protonation, generating a primary amine that subsequently acts as a 
nucleophile, and the process is repeated in subsequent propagation steps. The polymer thus formed retains the initiator nucleophile covalently bonded at one of its ends.

\section{$<$ Figure 1 $>$}

The presence of polyalanine side chains was supported by the infrared spectra, as shown in Figure 2. The residual amide group of chitosan shows bands at $1646 \mathrm{~cm}^{-1}$ and $1592 \mathrm{~cm}^{-1}$, as shown in Figure 2(a). The characteristic absorption bands of amide groups in Ala-g-Cts copolymers were evident at $1616 \mathrm{~cm}^{-1}$ and $1582 \mathrm{~cm}^{-1}$ and became stronger as the degree of grafting of $L$-alanine increased; conversely, the complex bands at 1050 to $1200 \mathrm{~cm}^{-1}$ due to a pyranose ring became relatively weaker, as shown in Figure 2(b-d).

\section{$<$ Figure 2 $>$}

Figure 3 shows the ${ }^{1} \mathrm{H}$ NMR spectra of Ala-NCA, Cts, and Ala-g-Cts copolymers. The ${ }^{1} \mathrm{H}$ NMR spectrum of chitosan is shown in Figure 3(b). The signal centered at $2.05 \mathrm{ppm}$ corresponds to the hydrogens of the methyl moieties belonging to the acetamido groups. The signal observed between 3.10 and $2.90 \mathrm{ppm}$ corresponds to the hydrogen bonded to the $\mathrm{C} 2$ glucosamine ring, while the signals between 3.30 and $4.00 \mathrm{ppm}$ correspond to hydrogens bonded to the carbon atoms $\mathrm{C} 3, \mathrm{C} 4, \mathrm{C} 5$ and $\mathrm{C} 6$ of the glucopyranose that are overlapped. The hydrogen bonded to the anomeric carbon (C1) gives rise to the signals in the range 4.50-4.90 ppm. The grafting of alanine onto Cts by a ring-opening reaction is confirmed by the presence in the ${ }^{1} \mathrm{H}$ NMR peaks at 1.35 and 3.60 ppm due to methyl protons of alanine and C$\mathrm{H}$ proton, respectively. The peaks around $1.35 \mathrm{ppm}$ attributed to the methyl group increased according to the molar ratio of $L$-alanine to Cts in Figure 3(c-e). The alanine group on the chitosan backbone was calculated from the relative integrations of the methyl protons at 1.35 ppm with respect to the methyl protons of the acetyl group at $2.05 \mathrm{ppm}$. These calculations 
correlate with the elemental analysis data with degree of alanine, 0.96 for Ala-g-Cts 1, 2.92 for Ala-g-Cts3 and 4.85 for Ala-g-Cts5.

$<$ Figure 3 $>$

\section{Solubility of Ala-g-Cts copolymers}

The solubility behaviors of Ala-g-Cts films were presented in Table 1. All Ala-g-Cts powder and films became soluble in water, DMSO and DMF, in addition, the solubility increased as the content of alanine increased in organic solvent. However, they were swellable or partially soluble in THF, methanol and chloroform. The solubility of Ala-g-Cts copolymers are attributed to their partial destruction of crystalline structure and little hydrogen bonding between amino and hydroxyl groups.

$<$ Table 1 $>$

\section{$X$-ray diffraction (XRD) analysis}

We measured the x-ray powder diffraction of Cts and Ala-g-Cts copolymers, as illustrated in Figure 4. Poly(amino acid)s are known to crystallize easily. ${ }^{28}$ In general, the XRD patterns of all types of Cts show two crystalline peaks around $2 \theta=10.3$ degrees and 19.9 degrees. The crystalline peak centered at 10.3 degrees is attributed to the hydrated crystalline form I of Cts. Another peak registered near 19.9 degrees is reported to indicate the relatively regular crystal lattice (crystalline form II) of Cts. ${ }^{29,30}$ This is because Cts typically contains bound water even if it has been dried thoroughly. The convergence of bound water molecules with the crystal lattice, commonly termed hydrated crystals, generally gives rise to a more dominant polymorph that can normally be detected as a broad crystalline peak in the corresponding $\mathrm{x}$ ray pattern. In the XRD shown in Figure 4(b-d), the new characteristic peaks at 29.2, 30.6, 32.7, 34.5, and 45.9 degrees are due to the Ala-g-Cts. Compared with the original Cts, Ala-g- 
Cts showed a weaker and broader peak in the $2 \theta=15$ to 21 degrees region, which demonstrated that the conjugation of alanine with Cts suppressed the crystallization of Cts to some extent. In addition, it can be seen that the crystallinity increased significantly for Ala-gCts as the molar ratio of the alanine increased. The clear, sharp signals appeared at $2 \theta=29.2$ to 34.5 degrees and increased. In all likelihood, $L$-alanine branches was sensitive to crystallization as in poly(amino acid)s.

$<$ Figure 4>

\section{DSC and TGA analyses}

The thermal stability of the Cts and Ala-g-Cts was investigated by means of DSC and TGA, as shown in Figure 5. It can be seen that three consecutive weight-loss steps were observed in the pure Cts and Ala-g-Cts (Figure 5(a)). The first weight loss was about $5.0 \mathrm{wt} \%$ up to $110^{\circ} \mathrm{C}$, which was responsible for the loss of vaporization of the absorbed and bound water, indicating their hygroscopic nature. The second weight loss of about 40 to $45 \mathrm{wt} \%$ between $240^{\circ} \mathrm{C}$ and $245^{\circ} \mathrm{C}$ was due to the thermal degradation of alanine linkage in the Ala-g-Cts. The third stage showed a weight loss that was responsible for the thermal decomposition of the glucosamine residue. Ala-g-Cts polymers showed almost similar behavior, with weight loss between $230^{\circ} \mathrm{C}$ and $530^{\circ} \mathrm{C}$, indicating less stability relative to Cts.

DSC thermograms of Cts and Ala-g-Cts in the heating run are shown in Figure 5(b). The Ala-g-Cts copolymer exhibited a sharp exothermic peak at approximately $250^{\circ} \mathrm{C}$, indicating decomposition of the alanine linkage. The exothermic peak at $306^{\circ} \mathrm{C}$ was due to decomposition of the Cts backbone, while the exothermic peak of the Ala-g-Cts copolymer was shifted to a lower temperature at $238^{\circ} \mathrm{C}$. Therefore, the endothermic and exothermic peaks of the Ala-g-Cts copolymer drifted farther to the left than those of Cts, perhaps owing to a reduction in the size of the crystals. Because of the differences in chemical and structural 
characteristics, we witnessed remarkable differences in the exothermic transitions in Cts, Alag-Cts1, Ala-g-Cts3, and Ala-g-Cts5.

Generally, the glass transition temperature $\left(T_{g}\right)$ is read at the initial change in the slope of the heat capacity of the DSC thermogram (i.e., the temperature at the onset of a baseline step in the DSC curve). The DSC thermogram peaks of Cts and Ala-g-Cts shown in Figure 5(b) can be attributed to glass transition. The $\mathrm{T}_{\mathrm{g}}$ for $\mathrm{Cts}$ was reported to be $203^{\circ} \mathrm{C}$ by Sakurai et al. ${ }^{31}$ However, the $\mathrm{Cts}$ and Ala-g-Cts showed obvious $\mathrm{T}_{\mathrm{g}}$ regions at $200^{\circ} \mathrm{C}$ and $127^{\circ} \mathrm{C}$ to $177^{\circ} \mathrm{C}$, respectively. In this study, it is possible that the derivatives have less thermal stability than the Cts, particularly the Ala-g-Cts5 copolymer.

$<$ Figure $5>$

\section{Rheological properties}

Measurements of viscosity and viscoelastic properties are as important as the characteristics of the biomaterial. Figure 6(a) shows the effect of temperature on shear stress as a function of shear rate of $1 \%$ Ala-g-Cts copolymer solutions. When the shear rate increased, the shear stress increased for all three solutions (Ala-g-Cts1, Ala-g-Cts3, and Ala-g-Cts5). As a rule, shear stress increased with increasing shear rate at lower temperatures. The viscosity of the Ala-g-Cts1 solution was higher than that of the Ala-g-Cts3 and Ala-g-Cts5 solutions and depended upon shear conditions. It is clear that the viscosity of these solutions corresponds to non-Newtonian behavior. The viscosity of Ala-g-Cts was dependent on the content of AlaNCA. In other words, the viscosity of the Ala-g-Cts solutions decreased as the $L$-alanine moiety in the Cts chain increased. Typical viscosity-versus-shear rate curves are shown in Figure 6(b). The difference in apparent viscosity between the Ala-g-Cts copolymers at $25^{\circ} \mathrm{C}$ and $37^{\circ} \mathrm{C}$ is related to the shear stress values, since the apparent viscosity is a ratio between shear stress and shear rate. With an increase in shear rate there is a decrease in apparent 
viscosity of the Ala-g-Cts solutions. When shear force is applied, the polymer molecules start to untangle from each other and to align themselves in the direction of flow. In the strict sense, the rheological behavior of a plastic is a combination of non-Newtonian and Newtonian behaviors. At lower shear rates, the plastic is non-Newtonian but as the shear rate increases, the plastic tends to exhibit Newtonian behavior. ${ }^{32}$

Figure 6(c) shows changes in the modulus of a mixture of Ala-g-Cts solutions with glutaraldehyde ( $3 \%$ molar ratio of Ala-NCA) as a function of temperature at $25^{\circ} \mathrm{C}$ and $37^{\circ} \mathrm{C}$, respectively. Ala-g-Cts/glutaraldehyde solutions undergo a sol-gel transition as the temperature increases. The viscosity of Ala-g-Cts/glutaraldehyde solutions increased from $10^{4}$ to $5 \times 10^{4} \mathrm{mPa}$ as the temperature increased from $20^{\circ} \mathrm{C}$ to $60^{\circ} \mathrm{C}$ at $\mathrm{pH} 3.0$ and $\mathrm{pH} 6.0$. At higher temperatures, the water phase became rigid, consistent with the formation of a gel. This remarkable change in fluidity upon heating and cooling was irreversible. At higher $\mathrm{pH}$, the crosslinking reaction was initiated more rapidly and the resulting viscosity maintained lower values. According to this study of chemical crosslinking of Ala-g-Cts solutions, gel formation has been confirmed.

$<$ Figure 6 $>$

\section{Swelling behaviors of crosslinked Ala-g-Cts}

The swelling behaviors of Ala-g-Cts films using gravimetric methods are presented in Figure 7. As expected, the crosslinking of Ala-g-Cts films suppressed the swelling. This effect was proportional to the degree of crosslinking, which can be attributed to the hydrophobic character of the crosslinking agent. Glutaraldehyde crosslinking was used for the Cts and Alag-Cts films: covalent crosslinking of Ala-g-Cts films with $0.5 \%$ glutaraldehyde solution. In addition, it is another anticipated approach for modulating a broad spectrum of characteristics of Ala-g-Cts-based biomaterials for neogenesis. Typically, the crosslinking density increases; 
as the concentration of the crosslinking agent increases within a certain range, the degree of swelling decreases. ${ }^{33,34}$ In the case of Cts and Ala-g-Cts films, the mechanical strength and the releasing profiles of cell growth and bioactivity can also be regulated by crosslinking. Ala-g-Cts copolymers have amide groups, which are considered hydrophilic. When the crosslinking reaction takes place, the crosslinking agent reacts with the amide and amine groups of Ala-g-Cts by glutaraldehyde linkage. Therefore, these hydrophilic groups are incorporated into the crosslinking chain, increasing its hydrophobicity after crosslinking. The mobility of the polymer chain is decreased by the formation of a polymeric network. The Alag-Cts5 film swelled less than the Ala-g-Cts3 and Ala-g-Cts1 films did. This result could be attributed to several factors, such as a decrease in chain mobility or solubility, as the crosslinking agent reacts with the amino group of Ala-g-Cts. ${ }^{35}$ The equilibrium swelling degree of chitosan with degree of deacetylation $81 \%$ matrices was $200 \%{ }^{36}$

$<$ Figure $7>$

\section{Mechanical properties}

Figure 8 illustrates the typical stress-strain curves of Ala-g-Cts films and their crosslinked films with glutaraldehyde. The curves show that Ala-g-Cts1 film was stiffer and had a higher than the Ala-g-Cts3 and Ala-g-Cts5 films. Chemically crosslinking of Ala-g-Cts films using glutaldehyde was found to result in increased strength. Stress at failure increased 2-fold compared with non-crosslinked film. It is likely that the crosslinking process pulls polymer chains closer together in the formation of inter-chain bonds and thus produces a denser, smoother structure. These inter-chain bonds provide additional strength to the films and prevent chain sliding, therefore providing mechanical stability to the films.

$<$ Figure $8>$ 
Figure 9 shows a representative Young's modulus obtained from tensile tests for all the films under study. The Young's modulus of crosslinked Ala-g-Cts films varied, ranging from 1.5 to 6.3 $\mathrm{MPa}$, depending on the grafted molar ratio of $L$-alanine. The Young's modulus increased slightly for crosslinked Ala-g-Cts film compared with non-crosslinked film (Ala-g-Cts $1=1.4$ $\mathrm{MPa}$, Ala-g-Cts3 $=2.9 \mathrm{MPa}$ and Ala-g-Cts5 $=5.4 \mathrm{MPa}$. All other non-crosslinked films were too weak to be tested in tension in ultimate tesile strength (UTS) values (Figure 9(b)). Those Ala-g-Cts5 films that are present are unlikely to be fully interconnected due to the surrounding polyalanine moiety, and thus provide limited mechanical benefit. Even the crosslinking process did not alter the soft structure of Ala-g-Cts3 and Ala-g-Cts5 films, which have some of their crystallization structure suppressed by the conjugation of alanine with Cts. The tensile stress and elastic modulus of chitosan were $52.90 \mathrm{MPa}$ and $20.37 \mathrm{MPa}$, respectively. ${ }^{37}$

$<$ Figure $9>$

\section{Enzymatic degradation studies}

The biodegradation results of crosslinked Ala-g-Cts films are shown in Figure 10. In general, the enzymatic biodegradation ingredients are dependent on $\mathrm{pH}$, temperature, chain mobility, and crystallinity. The in vitro biodegradation behavior of Cts has usually been investigated using lysozyme from chicken egg whites. ${ }^{38-40}$ Figure 11 shows scanning electron microscopic images obtained for the crosslinked Ala-g-Cts1, Ala-g-Cts3, and Ala-g-Cts5 films after 10, 20, and 30 days of exposure in PBS with lysozyme $(1 \mathrm{mg} / \mathrm{mL})$ at $37^{\circ} \mathrm{C}$. In the presence of lysozyme, crosslinked Ala-g-Cts1 and Ala-g-Cts3ilms showed rapid loss of mass for up to 25 days. However, the crosslinked Ala-g-Cts5 film decomposed very rapidly after 15 days. There are plenty of reasons for these enzymatic degradation rates. Biodegradation behavior of the crosslinked Ala-g-Cts films must be swelling and mobility of materials in PBS. The 
chemical modification of polymeric crosslinked film can control the rate of biodegradation. The weight loss percent almost reached degradation after 35 days of enzymatic degradation. But for the crosslinked Ala-g-Cts3 film, the weight loss percent was the lowest degradation behavior in the samples, and degradation almost ceased around weight loss $80 \%$. The weight of chitosan matrices with degree of deacetylation $81 \%$ remained relatively constant throughout degradation during 84 days. ${ }^{36}$

$<$ Figure $10><$ Figure $11>$

\section{In vitro cytotoxicity assessment}

Dehydrogenase-based assays of CCK-8 provide greater sensitivity than the other assays because they depend on several elements, including dehydrogenase, NAD(H), NADP(H), and mitochondrial activity. CCK-8 is a colorimetric assay used to determine the number of viable cells and can be used as a cell proliferation assays as well as for cytotoxicity. When using CCK-8 as a proliferation or cytotoxicity assay, it is necessary to have a proportional relationship between absorption and viable cell numbers. It is desirable to start with a set number of cells and then determine the suitable incubation time for color development.

In this study, cell attachment was assessed based on cell viability and cytotoxicity on Cts and crosslinked Ala-g-Cts films. ${ }^{41,42}$ MC3T3-E1 cells were used because they are highly sensitive to culture conditions. The cells were cultured on Cts and crosslinked Ala-g-Cts films in order to analyze the influence of the graft polymer with respect to biocompatibility. The proliferation of MC3T3-E1 cells on crosslinked Ala-g-Cts films was investigated using the CCK-8 assay. It has been reported that the cellular response to biomaterials involves the cells' attachment to the substrate and the cells' spreading on the substrate. ${ }^{43,44}$ The cells on both the Cts and the crosslinked Ala-g-Cts films increased steadily throughout the incubation period for up to 7 days. Overall, the cells increased by nearly 3 to 5 times as much during the same 
period. The optical densities at $450 \mathrm{~nm}$ for Ala-g-Cts3 film were $0.21,0.34,0.58$, and 0.79 after 1-, 3-, 5- and 7-day cultures, respectively, indicating that the number of cells on the film had increased significantly.

The results of CCK-8 absorbance values for MC3T3-E1 cells' adhesion to and proliferation on the crosslinked Ala-g-Cts1, Ala-g-Cts3, and Ala-g-Cts5 films, as compared with those of the control, are shown in Figure 12. The initial proliferation rate of cell growth increased as the $L$-alanine content increased. The films with a greater $L$-alanine content showed cell proliferation, which was particularly remarkable in terms of biocompatibility. All the cells on the three crosslinked Ala-g-Cts films showed a higher rate of proliferation than that of the control, and the modified films were considered to be cytocompatible and nontoxic.

$<$ Figure 12>

\section{Conclusions}

Biocompatible $L$-alanine-grafted chitosan containing different amounts of the $L$-alanine moiety were synthesized via anionic ring-opening polymerization of $\mathrm{N}$-carboxyanhydride (Ala-NCA) onto chitosan. Depending on variations in the ratio of $L$-alanine in the copolymer, a variety of modified chitosan, which were easily dissolved in water and some organic solvents, with different thermal, morphological, and mechanical properties could be achieved. The MC3T3-E1 cells on crosslinked Ala-g-Cts films showed a higher rate of proliferation than that of the control, and the crosslinked Ala-g-Cts copolymers were considered to be cytocompatible and nontoxic. These crosslinked Ala-g-Cts copolymers were soft, flexible, and degradable polymers, which opens up a range of opportunities for soft tissue augmentation and regeneration.

\section{Declaration of conflicting interests}


The author(s) declared no potential conflicts of interest with respect to the research, authorship, and/or publication of this article.

\section{Funding}

This study was supported by Priority Research Centers Program (no. 2009-0093829) through the National Research Foundation of Korea. 


\section{References}

1. Rinaudo M. Chitin and chitosan: properties and applications. Prog Polym Sci 2006; $31: 603-633$

2. Bagheri-Khoulenjani S, Taghizadeh S.M, et al. An investigation on the short-term biodegradability of chitosan with various molecular weights and degrees of deacetylation. Carbohydr Polym 2009; 78: 773-778.

3. Varum KM, Myhr MM, et al. In vitro degradation rates of partially N-acetylated chitosans in human serum. Carbohydr Res 1997; 299: 99-101.

4. VandeVord PJ, Matthew HWT, et al. Evaluation of the biocompatibility of a chitosan scaffold in mice. J Biomed Mater Res 2002; 59: 585-590.

5. Sashiwa $\mathrm{H}$ and Aiba SI. Chemically modified chitin and chitosan as biomaterials. Prog Polym Sci 2004; 29: 887-908.

6. Illum L. Chitosan and its use as a pharmaceutical excipient. Pharm Res 1998; 15: 13261331.

7. Kumar M, Muzzarelli RAA, et al. Chitosan chemistry and pharmaceutical perspectives. Chem Rev 2004; 104: 6017-6084.

8. Park JH, Saravanakumar G, et al. Targeted delivery of low molecular drugs using chitosan and its derivatives. Adv Drug Deliv Rev 2010; 62: 28-41.

9. Panõs I, Acosta N, et al. New drug delivery systems based on chitosan. Curr Drug Discov Technol 2008; 5: 333-341.

10. Varshosaz J. The promise of chitosan microspheres in drug delivery systems. Expert Opin Drug Deliv 2007; 4: 263-273.

11. Madihally SV and Matthew HWT. Porous chitosan scaffolds for tissue engineering. Biomaterials 1999; 20: 1133-1142. 
12. Lehr C-M, Bouwstra JA, et al. In vitro evaluation of mucoadhesive properties of chitosan and some other natural polymers. Int J Pharm 1992; 78: 43-48.

13. Yang J, Tian F, et al. Effect of chitosan molecular weight and deacetylation degree on hemostasis. J Biomed Mater Res B Appl Biomater 2008; 84B: 131-137.

14. Minagawa T, Okamura Y, et al. Effects of molecular weight and deacetylation degree of chitin/chitosan on wound healing. Carbohydr Polym 2007; 67: 640-644.

15. Sudarshan NR, Hoover DG, et al. Antibacterial action of chitosan. Food Biotechnol 1992; 6: $257-272$.

16. Ong SY, Wu J, et al. Development of a chitosan-based wound dressing with improved hemostatic and antimicrobial properties. Biomater 2008; 29: 4323-4332.

17. Belalia R, Grelier S, Benaissa M, et al. New Bioactive Biomaterials Based on Quaternized Chitosan. Food Chem 2008; 56: 1582-1588.

18. Britto D. de, Forato LA, et al. Determination of the average degree of quaternization of N,N,N-trimethylchitosan by solid state ${ }^{13} \mathrm{C}$ NMR. Carbohydr Polym 2008; 74: 86-91.

19. Liu XF, Guan YL, Yang DZ, et al. Antibacterial action of chitosan and carboxymethylated chitosan. J Appl Polym Sci 2001; 79: 1324-1335.

20. Jeong YI, Kim DG, Jang MK, et al. Preparation and spectroscopic characterization of methoxy poly(ethylene glycol)-grafted water-soluble chitosan. Carbohydr Res 2008; 343: 282-289.

21. Tatsuro O, Hidetoshi N, and Yuichi O. Aggregation phenom-enon of PEG-grafted chitosan in aqueous solution. Polymer 1998; 39: 5171-5175.

22. Lee KY, Jo WH, Kwon IC, et al. Physicochemical characteristics of self-aggregates of hydrophobically modified chitosans. Langmuir 1998; 14: 2329-2332. 
23. Rúnarsson OV, Holappa J, Nevalainen T, et al. Antibacterial activity of methylated chitosan and chitooligomer derivatives: Synthesis and structure activity relationships. Eur Polym J 2007; 43: 2660-2671.

24. Timothy J and Deming M. Methodologies for preparation of synthetic block copolypeptides: materials with future promise in drug delivery. Adv Drug Delivery Reviews 2002; 54: 1145-1155.

25. Branden C and Tooze J, Introduction to Protein Structure. Garland Publishing, New York, 1991.

26. Kwon GS. Diblock copolymer nanoparticles for drug delivery. Crit Rev Ther Drug Carrier Syst 1998; 15: 481-512.

27. Kricheldorf HR. $\alpha$-Aminoacid- $N$-carboxyanhydrides. Garland Publishing, New York, 1991.

28. Zhigang Xu, Yaoyao Feng, Xiaoyan Liu, et al. Synthesis and characterization of $\mathrm{Fe}_{3} \mathrm{O}_{4} @ \mathrm{SiO}_{2} @$ poly-L-alanine, peptide brush-magnetic microspheres through NCA chemistry for drug delivery and enrichment of BSA. Colloids and surfaces B: Biointerfaces. 2010; 81: 503-507.

29. Mogilevskaya EL, Akopova TA, Zelenetskii AN and Ozerin AN. The crystal structure of chitin and chitosan. Polym Sci 2006; 48: 116-123.

30. Xiao B, Wan Y, Zhao MQ, Liu YQ and Zhang SM. Preparation and characterization of antimicrobial chitosan- $N$-arginine with different degrees of substitution. Carbohydr Polym 2011; 83: 144-150.

31. Sakurai K, Maegawa T and Takahashi T. Glass transition temperature of chitosan and miscibility of chitosan/poly( $N$-vinyl pyrrolidone) blends. Polymer 2000; 41: 7051-7056. 
32. Moghimipour E, Kouchak M, Salimi A, Bahrampour S, and Handali S, The effect of polymer content on the non-newtonian behavior of acetaminophene suspension, J Drug Delivery, 2013; 5: 2013.

33. Carmen RL and Roland B. Water uptake and permeability properties of crosslinked chitosan glutamate and alginate films. J Control Release 1997; 44: 215-225.

34. Li H, Wang X, Wang Z and Lam KY. Multiphysics modelling of volume phase transition of ionic hydrogels responsive to thermal stimulus. Macromol Biosci 2005; 5: 904-914.

35. Lin GS, Walls HJ, Kennedy SB and Welsh ER, Reaction kinetics and gel properties of blocked diisocyinate crosslinked chitosan hydrogels. Carbohyd polym 2003; 54: 193-199.

36. Ren D, Yi H, Wang W and Ma X, The enzymatic degradation and swelling properties of chitosan matrices with different degrees of N-acetylation. Carbohydr Res 2005; 340: $2403-2410$.

37. Rivero S, García M A, Pinotti A, Physical and chemical treatments on chitosan matrix to modify film properties and kinetics of biodegradation, J Mater Phys Chem 2013; 1: 51-57.

38. Etienne O, Schneider A, Taddei C, et al. Degradability of polysaccharides multilayer films in the oral environment: an in vitro and in vivo study. Biomacromolecules 2005; 6: $726-733$.

39. Freier T, Koh HS, Kazazian K and Shoichet MS. Controlling cell adhesion and degradation of chitosan films by N-acetylation. Biomaterials 2005; 26: 5872-5878.

40. Amarasekara AS, Opoku G, Qiu XD and Doctor V. Effect of oversulfation on the chemical and biological properties of chondroitin-6-sulfate. Carbohydr Polym 2007; 68: $116-121$. 
41. Salgado AJ, Gomes ME, Chou A, et al. Preliminary study on the adhesion and proliferation of human osteoblasts on starch-based scaffolds. Mater Sci Eng 2002; 20: 2733.

42. Wirth C, Grosgogeat B, Lagneau C, et al. Biomaterial surface properties modulate in vitro rat calvaria osteoblasts response: Roughness and or Chemistry. Mater sci Eng 2008; 28: $990-1001$.

43. Carter WG, Rauvala H and Hakomori SI. The kinetics of cell adhesion and cell spreading on surfaces coated with carbohydrate-reactive proteins (glycosidases and lectins) and Fibronectin. The journal of cell biology 1981; 88: 138-148.

44. Yoon JJ, Nam YS, Kim JH and Park TG, Surface immobilization of galactose onto aliphatic biodegradable polymers for hepatocyte culture. Biotechnology and Bioengineering 2002; 78: 1-10. 


\section{Figure Captions}

Figure 1. Anionic graft copolymerization of Cts with $L$-alanine- $N$-carboxyanhydrides (AlaNCA).

Figure 2. FT-IR spectra of (a) Cts, (b) Ala-g-Cts 1, (c) Ala-g-Cts3 and (d) Ala-g-Cts5. Cts: chitosan; Ala-g-Cts: $L$-alanine grafted chitosan.

Figure 3. ${ }^{1}$ H NMR spectra of (a) Ala-NCA, (b) Cts, (c) Ala-g-Cts5, (d) Ala-g-Cts3 and (e) Ala-g-Cts 1. Ala-NCA: $L$-alanine- $N$-carboxyanhydride; Cts: chitosan; Ala- $g$-Cts: $L$-alanine grafted chitosan.

Figure 4. X-ray diffraction patterns of (a) Cts, (b) Ala-g-Cts1, (c) Ala-g-Cts3 and Ala-g-Cts5. Cts: chitosan; Ala-g-Cts: $L$-alanine grafted chitosan.

Figure 5. (a) TGA and (b) DSC curves of Cts and Ala-g-Cts copolymers.

Figure 6. (a) Influence of temperature on the rheological curves of $1 \%$ Ala-g-Cts solutions, (b) viscosity of $3 \%$ Ala-g-Cts solutions versus shear rate at $25^{\circ} \mathrm{C}$ and $37{ }^{\circ} \mathrm{C}$, and (c) Sol-gel transition behavior of 3\% Ala-g-Cts as a function of temperature at $\mathrm{pH}$ of 3.0 and 6.0.

Figure 7. Swelling behavior of crosslinked Ala-g-Cts film samples in PBS at $37^{\circ} \mathrm{C}$.

Figure 8 . Tensile test curves of $A$ la-g-Cts films. Films were stabilized at $85 \pm 2 \%$ low relative humidity and $23 \pm 2{ }^{\circ} \mathrm{C}$ before testing.

Figure 9. (a) Young'modulus and (b) UTS of Ala-g-Cts films: Ala-g-Cts1, Ala-g-Cts3, and Ala-g-Cts5.

Figure 10. Mass loss of crosslinked Ala-g-Cts films in $1 \mathrm{mg} / \mathrm{mL}$ lysozyme in PBS at $37^{\circ} \mathrm{C}$.

Figure 11. SEM images of the surface of crosslinked Ala-g-Cts films, Ala-g-Cts1 (a, b, c), Ala-g- Cts3 (d, e, f) and (Ala-g-Cts5 (g, h, i) in enzyme within degradation after 10 days (a, d, $\mathrm{g}), 20$ days $(\mathrm{b}, \mathrm{e}, \mathrm{h})$ and 30 days $(\mathrm{c}, \mathrm{f}, \mathrm{i})$.

Figure12. Cell viability and proliferation results obtained using the CCK-8 test. For the control, the same amount of cells was seeded on 24 culture well plates. Cells were kept in culture for 1, 3, 5 and 7 days on Cts and Ala-g-Cts film. 

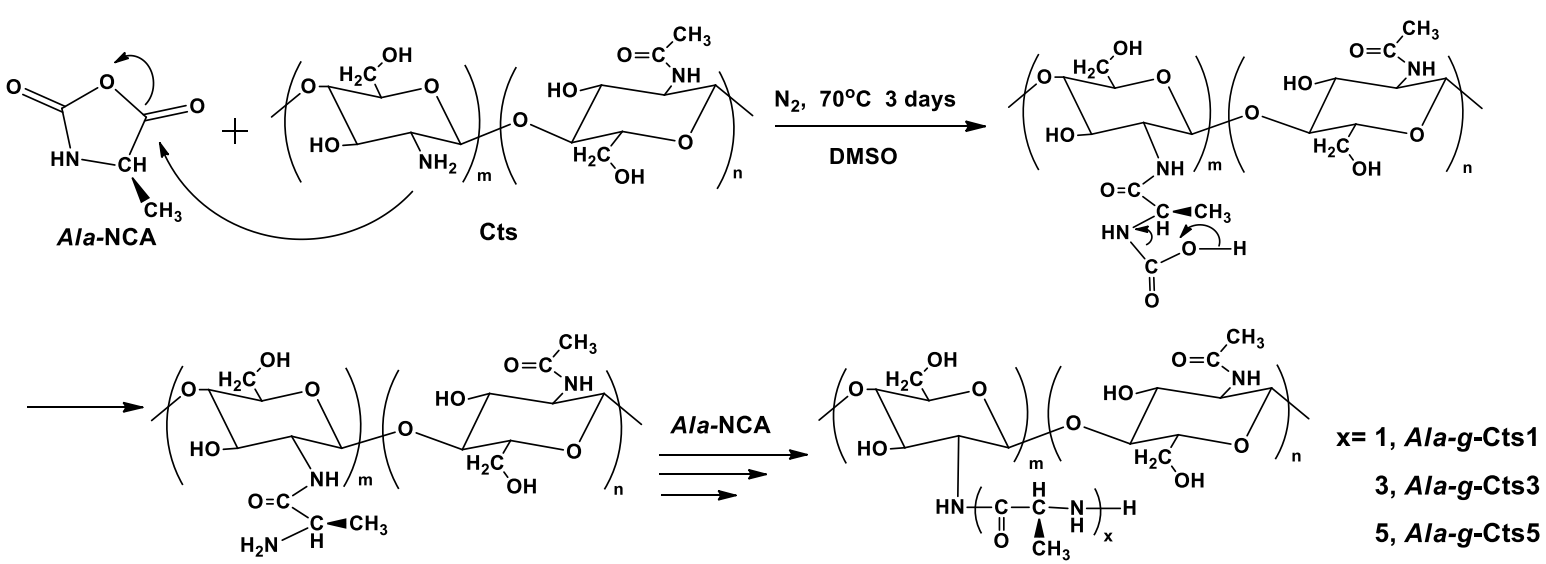

Figure 1. Anionic graft copolymerization of Cts with $L$-alanine- $N$-carboxyanhydrides (AlaNCA). 


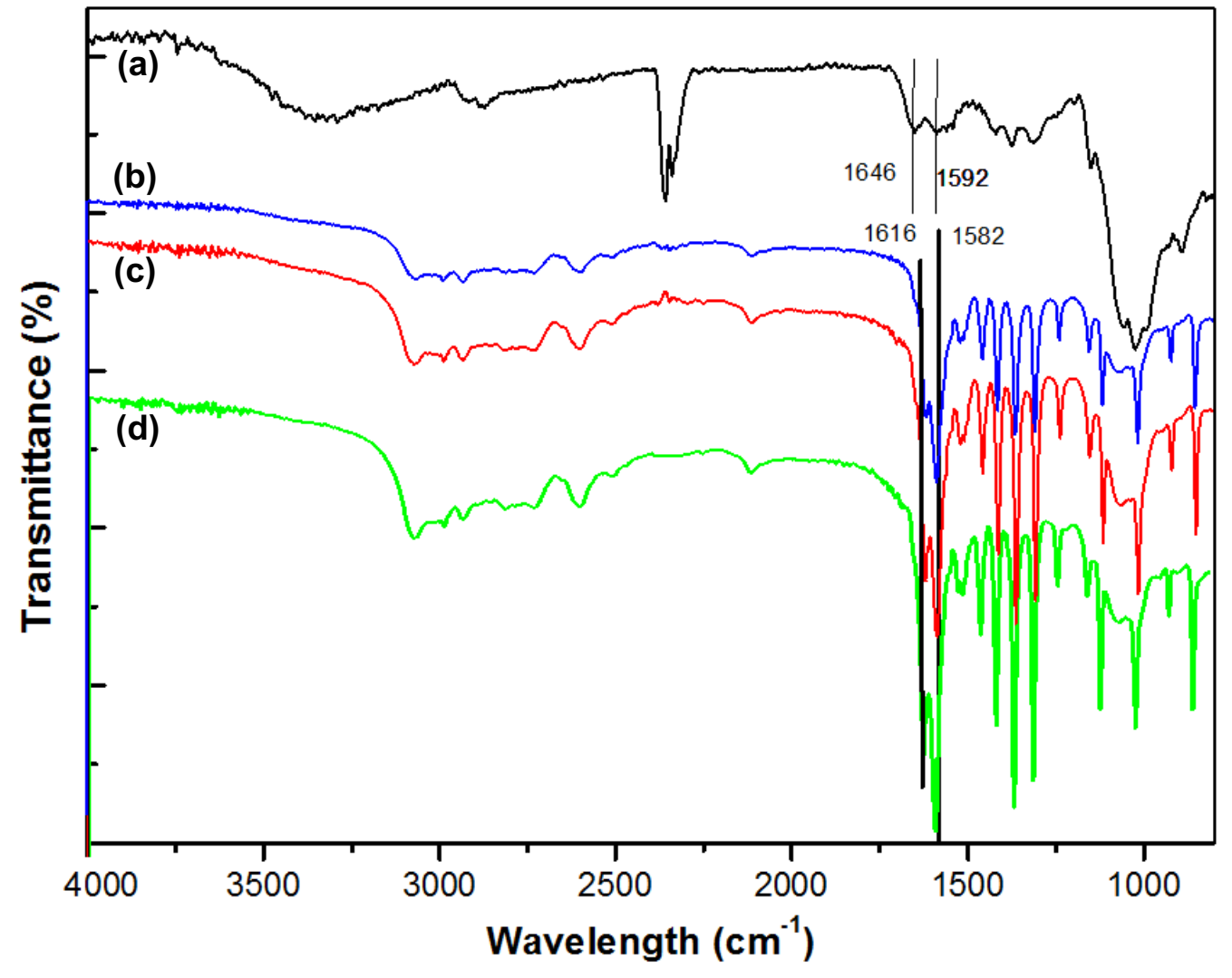

Figure 2. FT-IR spectra of (a) Cts, (b) Ala-g-Cts1, (c) Ala-g-Cts3 and (d) Ala-g-Cts5. Cts: chitosan; Ala-g-Cts: $L$-alanine grafted chitosan. 


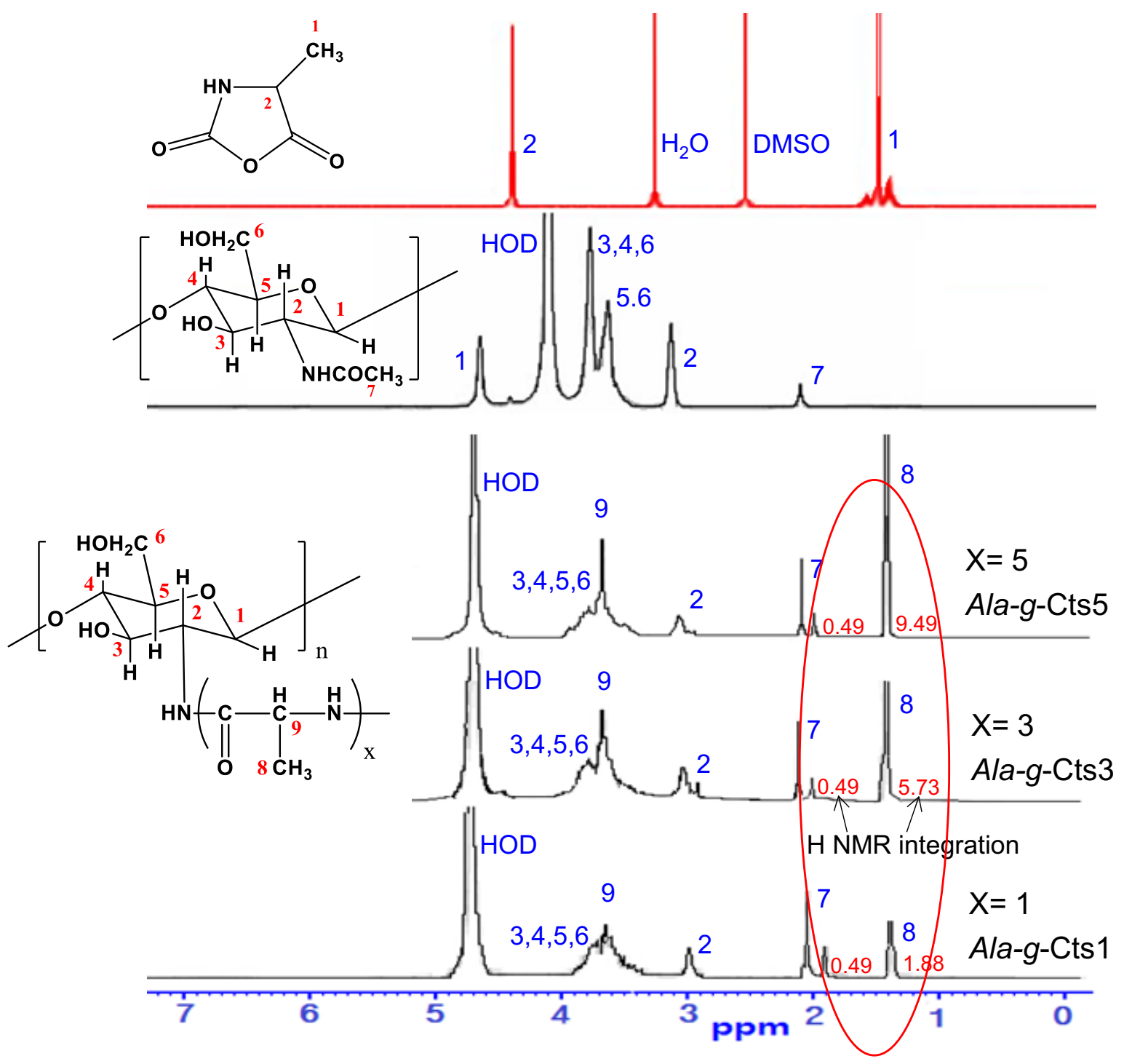

Figure 3. ${ }^{1} \mathrm{H}$ NMR spectra of (a) Ala-NCA, (b) Cts, (c) Ala-g-Cts5, (d) Ala-g-Cts3 and (e) Ala-g-Cts 1. Ala-NCA: $L$-alanine- $N$-carboxyanhydride; Cts: chitosan; Ala-g-Cts: $L$-alanine grafted chitosan. 


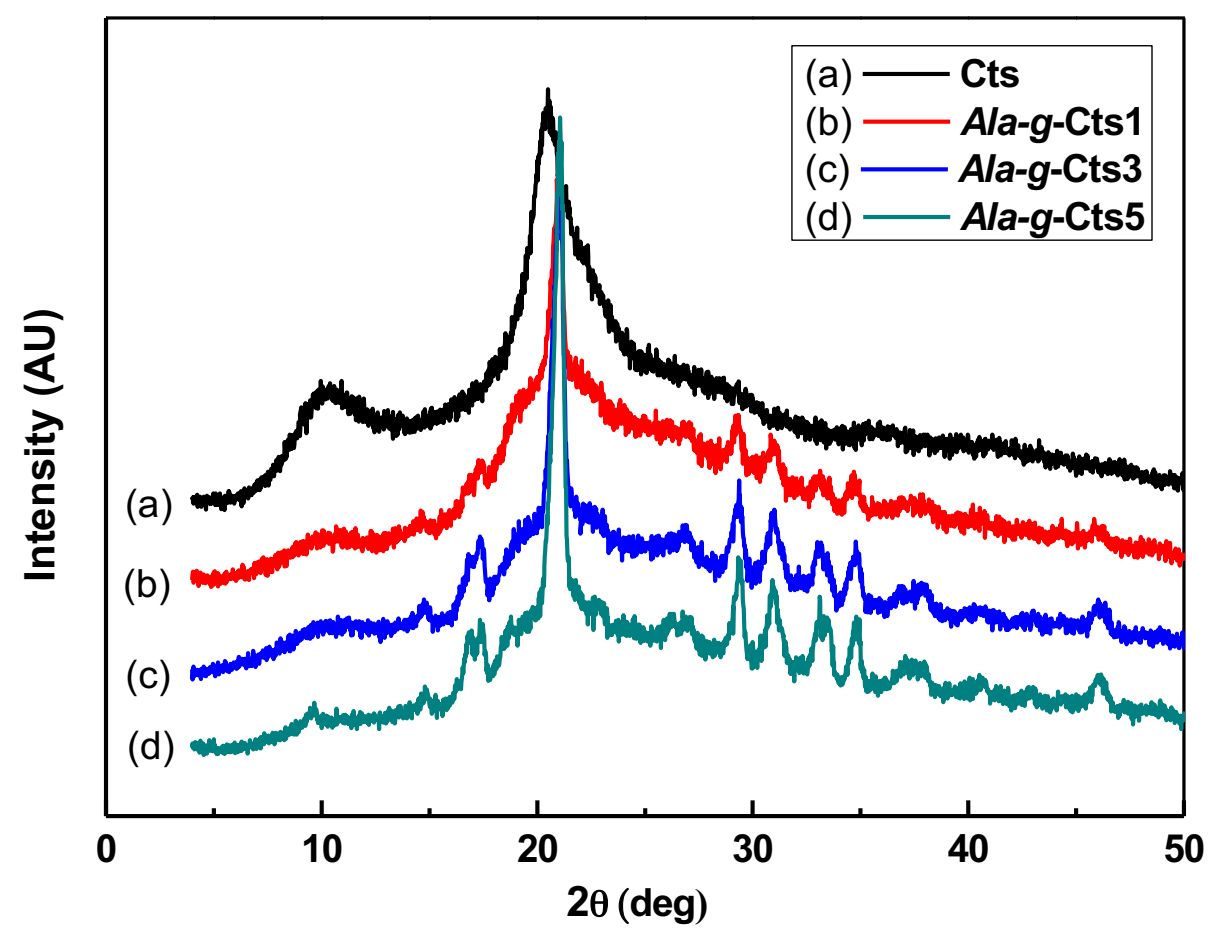

Figure 4. X-ray diffraction patterns of (a) Cts, (b) Ala-g-Cts1, (c) Ala-g-Cts3 and Ala-g-Cts5. Cts: chitosan; Ala-g-Cts: $L$-alanine grafted chitosan. 

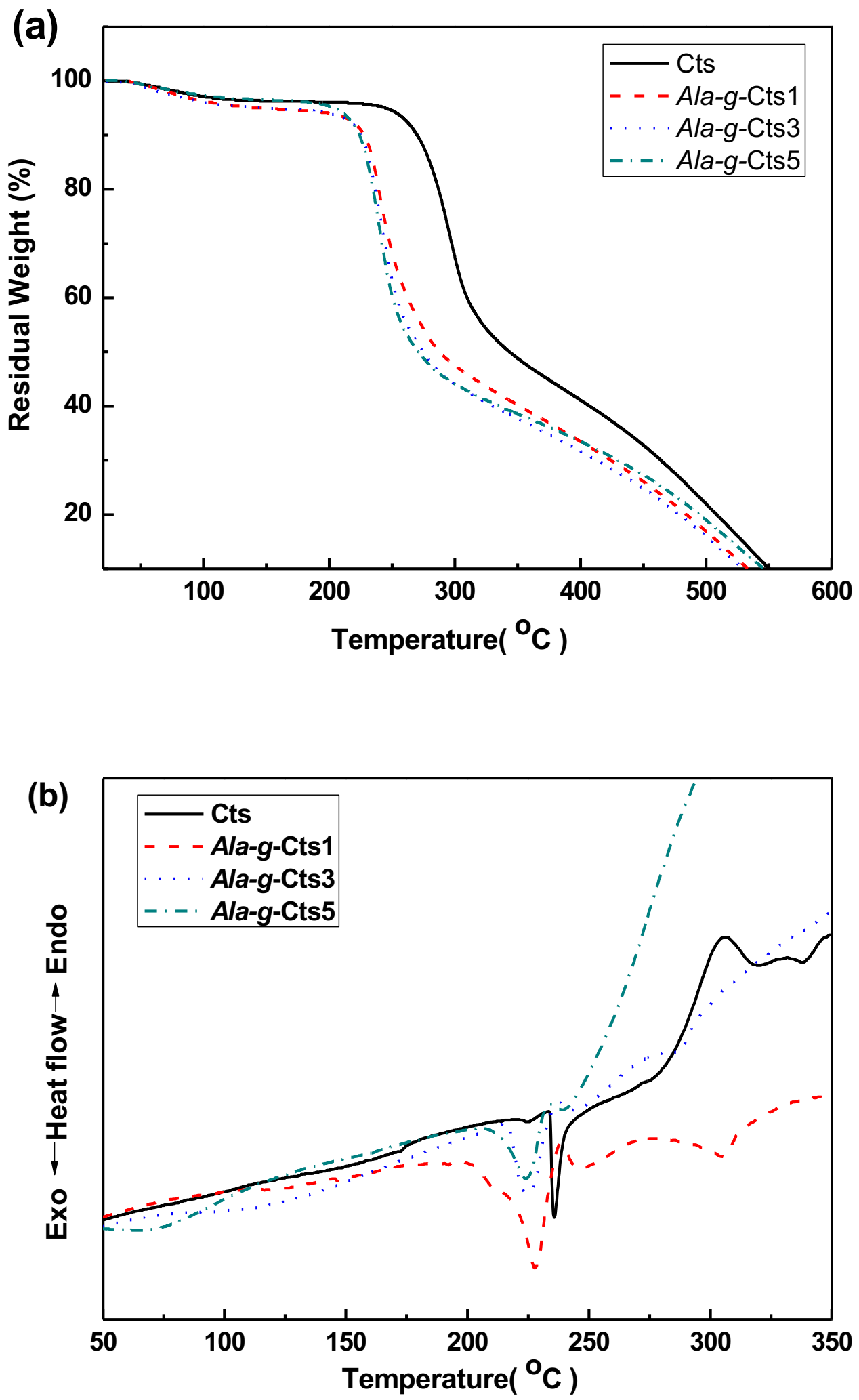
Figure 5. (a) TGA and (b) DSC curves of Cts and Ala-g-Cts copolymers. 

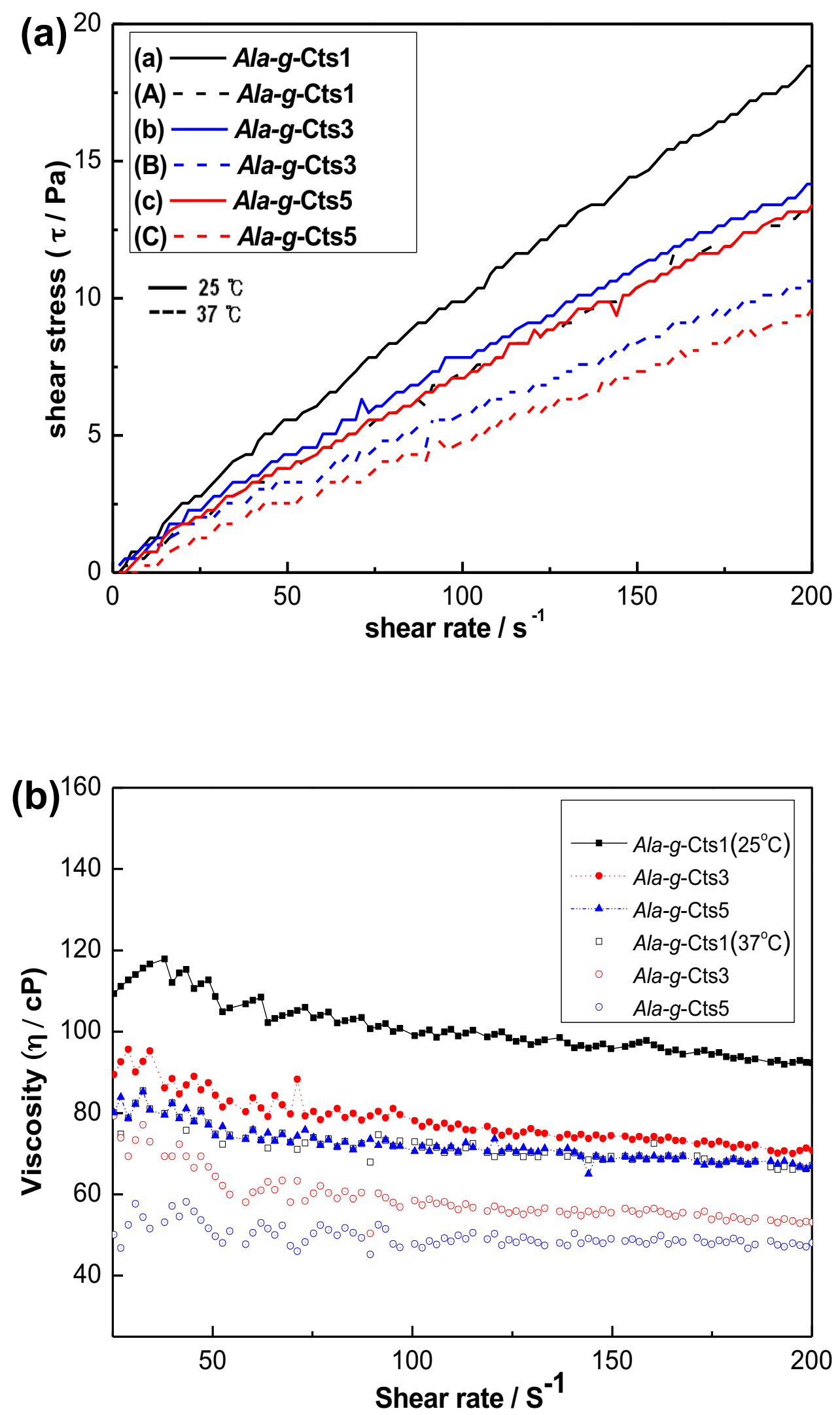


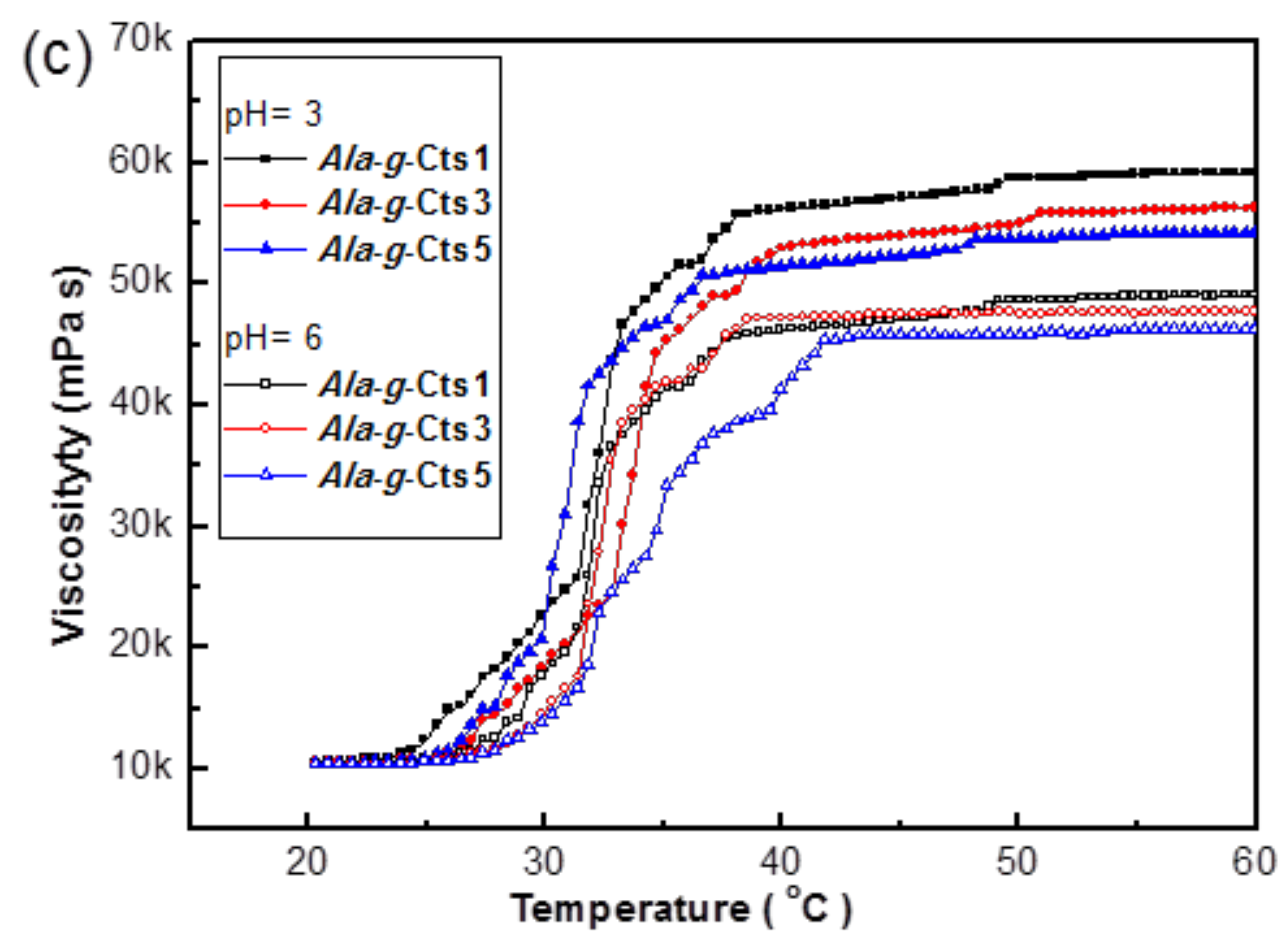

Figure 6. (a) Influence of temperature on the rheological curves of 1\% Ala-g-Cts solutions, (b) viscosity of $3 \%$ Ala-g-Cts solutions versus shear rate at $25{ }^{\circ} \mathrm{C}$ and $37^{\circ} \mathrm{C}$, and (c) Sol-gel transition behavior of $3 \%$ Ala-g-Cts as a function of temperature at $\mathrm{pH}$ of 3.0 and 6.0. 


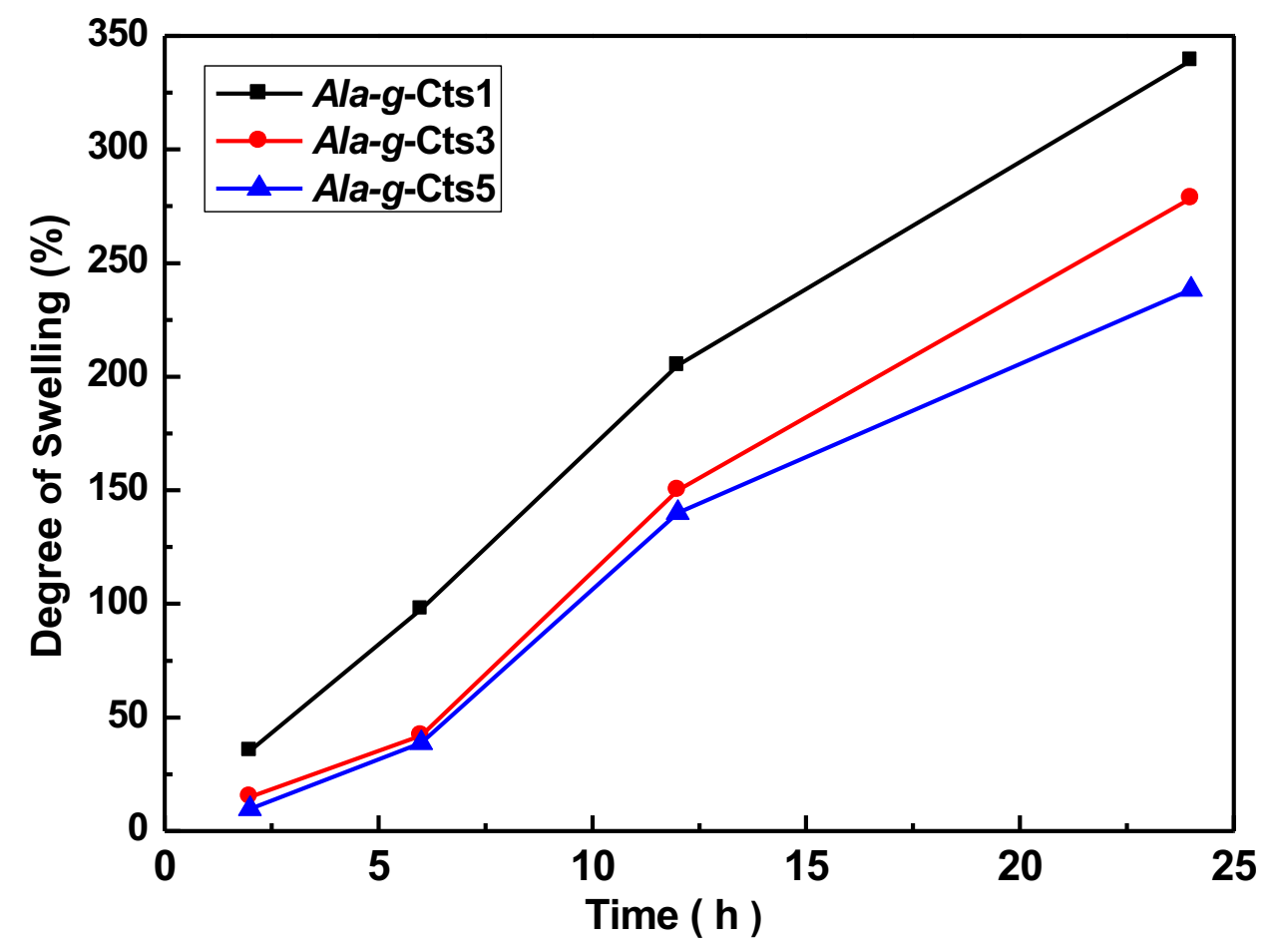

Figure 7. Swelling behavior of crosslinked Ala-g-Cts film samples in PBS at $37^{\circ} \mathrm{C}$. 


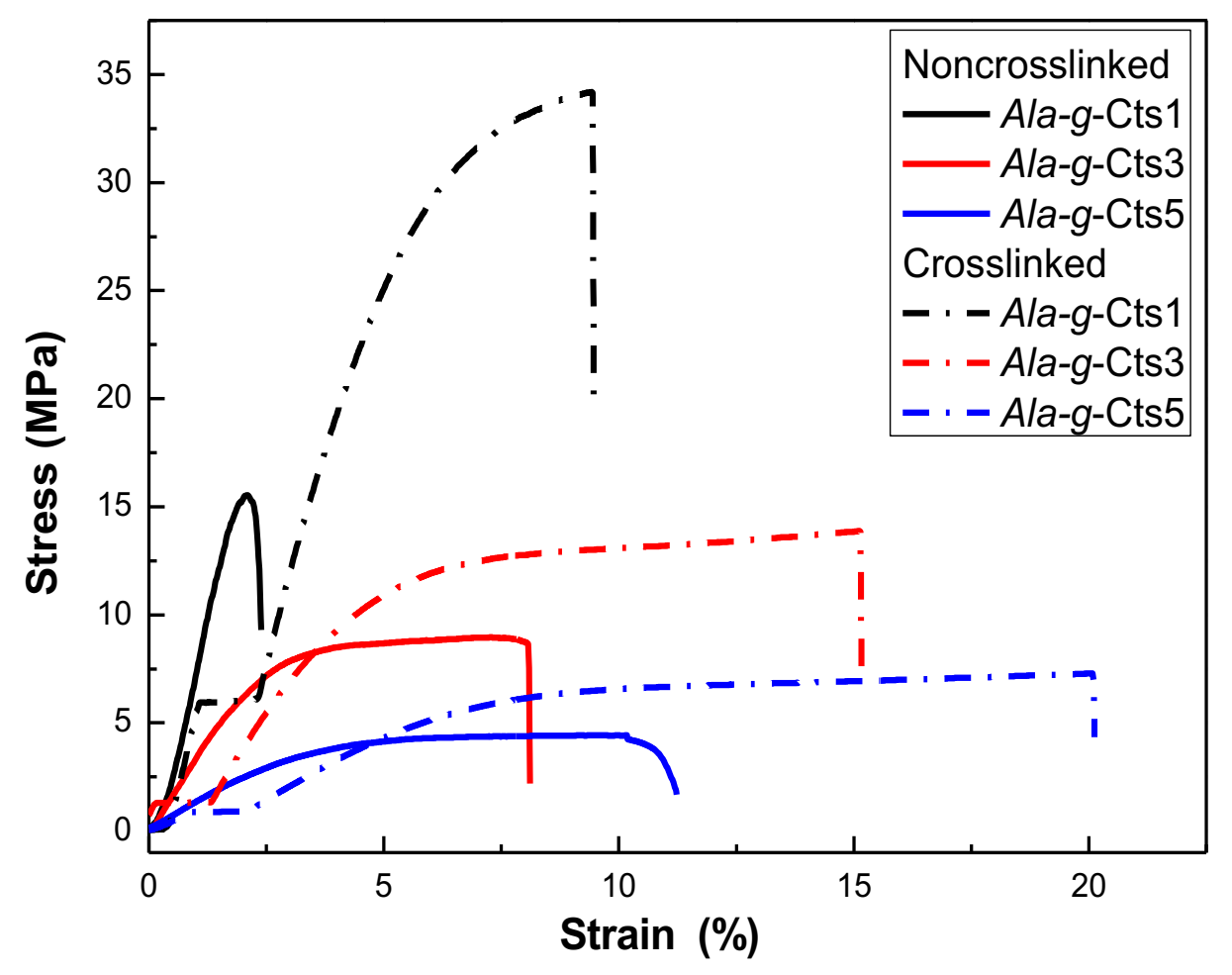

Figure 8. Tensile test curves of Ala-g-Cts films. Films were stabilized at $85 \pm 2 \%$ low relative humidity and $23 \pm 2{ }^{\circ} \mathrm{C}$ before testing. 

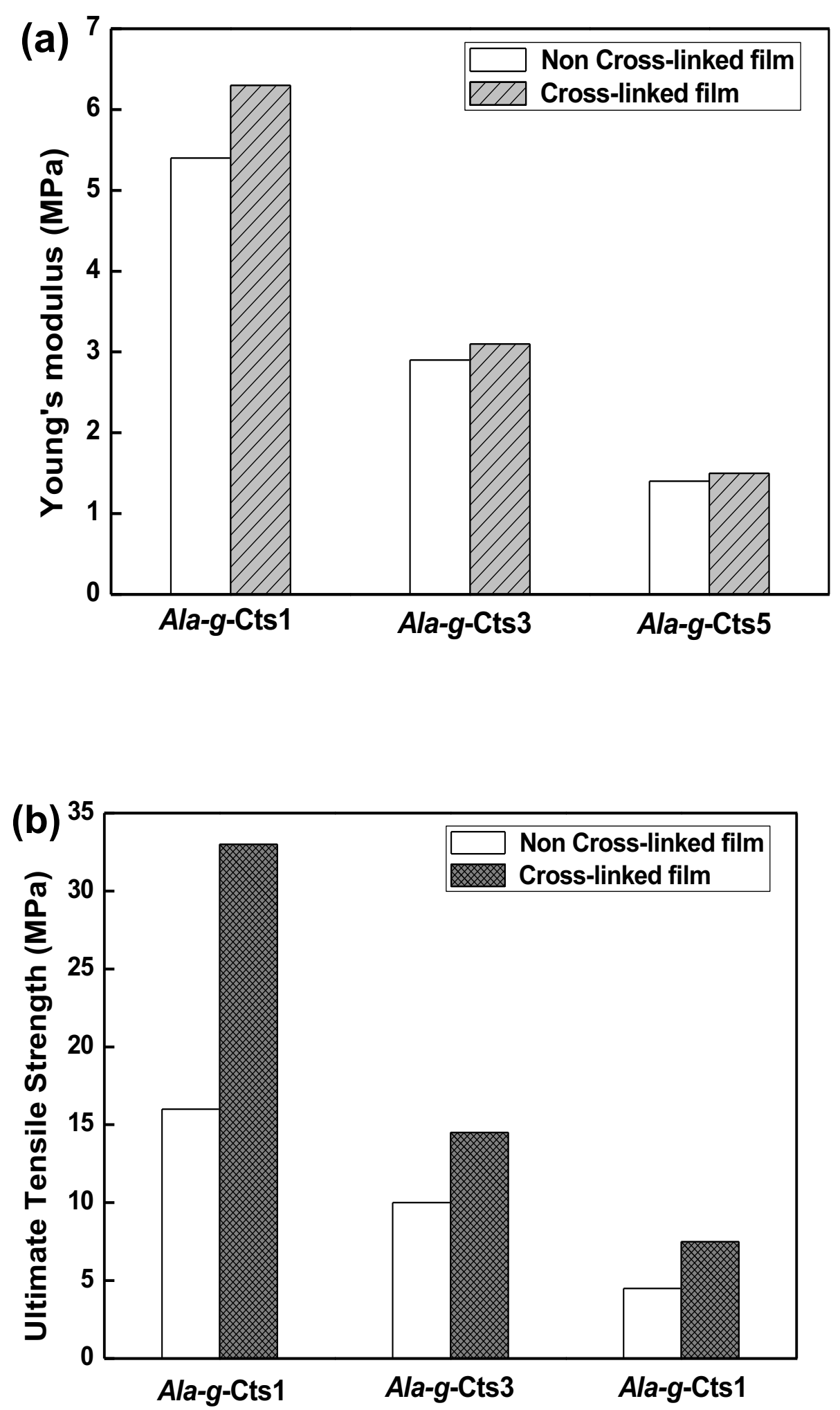

Figure 9. (a) Young'modulus and (b) UTS of Ala-g-Cts films: Ala-g-Cts1, Ala-g-Cts3, and Ala-g-Cts5. 


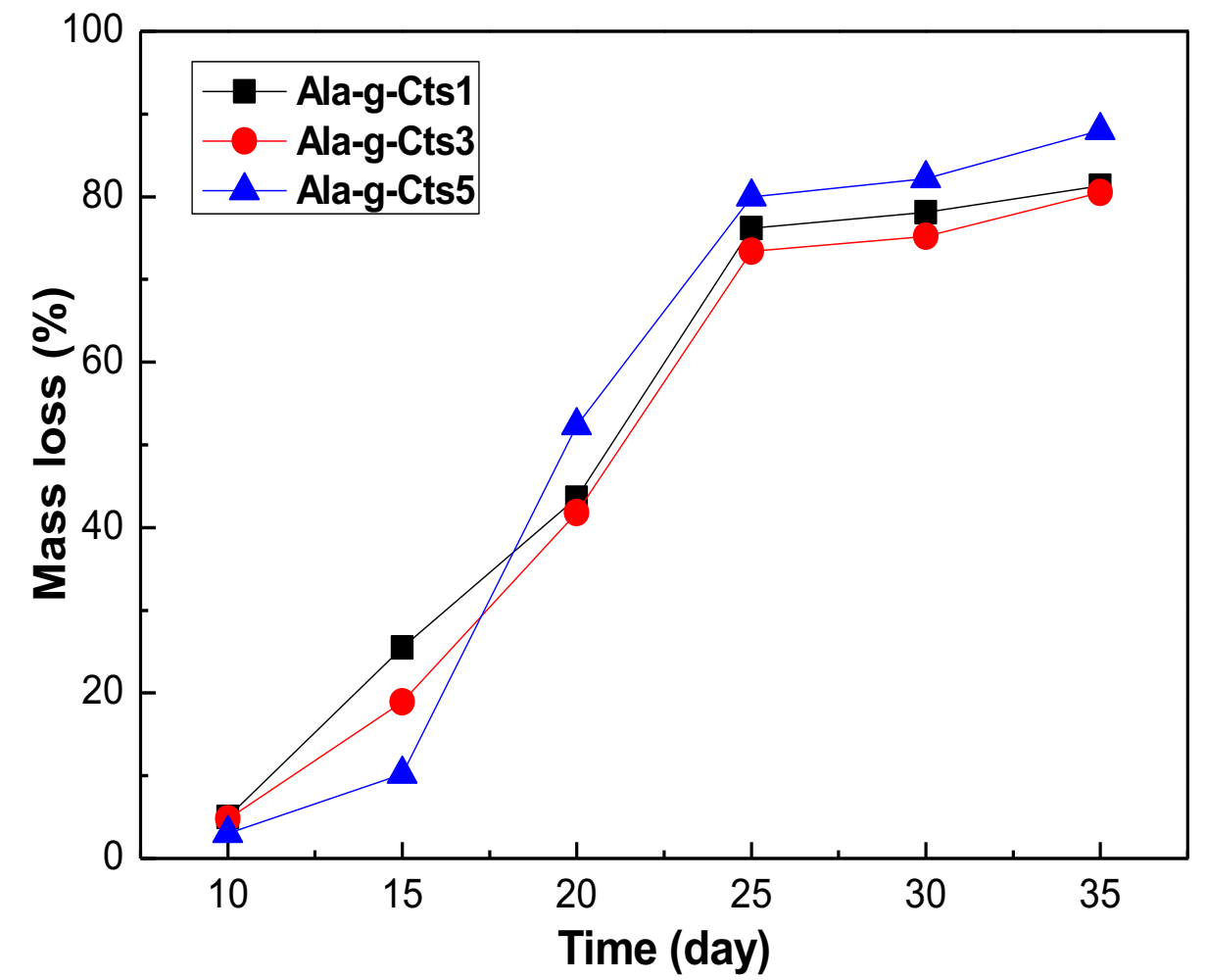

Figure 10. Mass loss of crosslinked Ala-g-Cts films in $1 \mathrm{mg} / \mathrm{mL}$ lysozyme in PBS at $37^{\circ} \mathrm{C}$. 

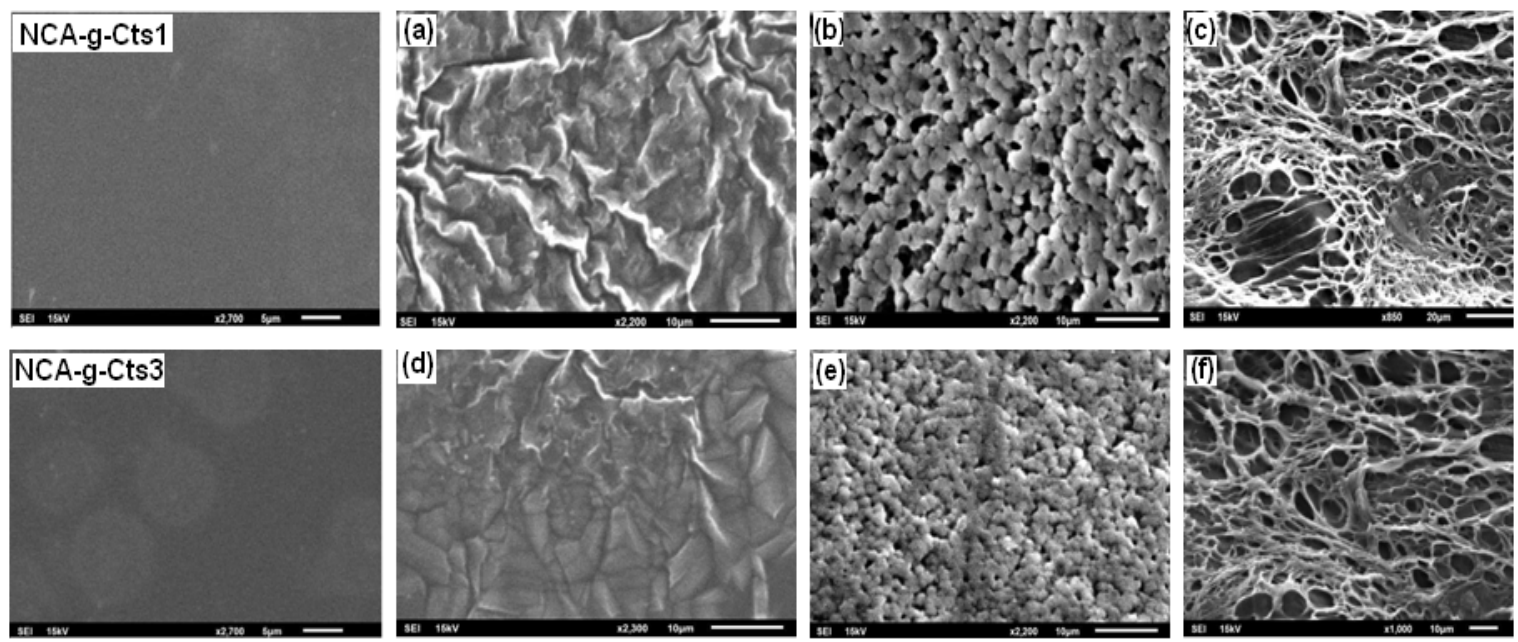

NCA-g-Cts5
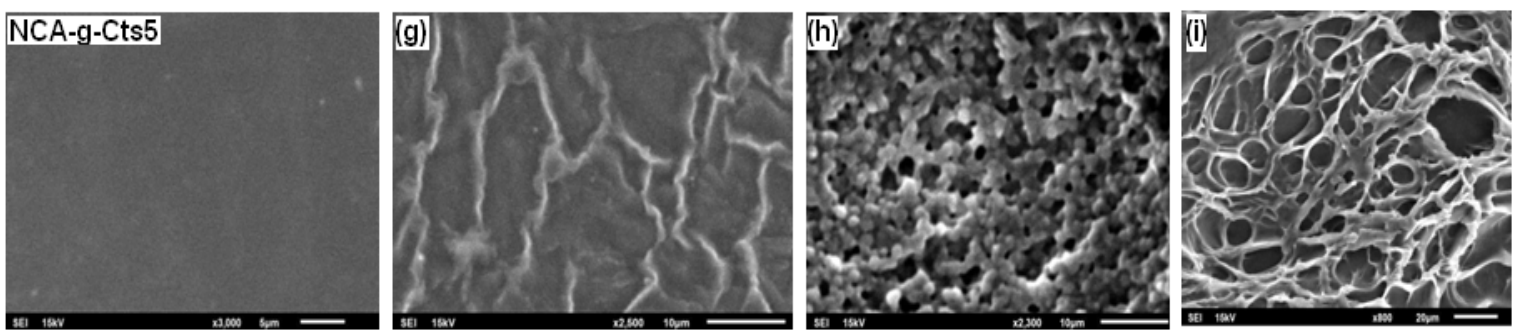

Figure11. SEM images of the surface of crosslinked Ala-g-Cts films, Ala-g-Cts1 (a, b, c), Ala-g- Cts3 (d, e, f) and (Ala-g-Cts5 (g, h, i) in enzyme within degradation after 10 days (a, d, g), 20 days $(b, e, h)$ and 30 days $(c, f, i)$. 


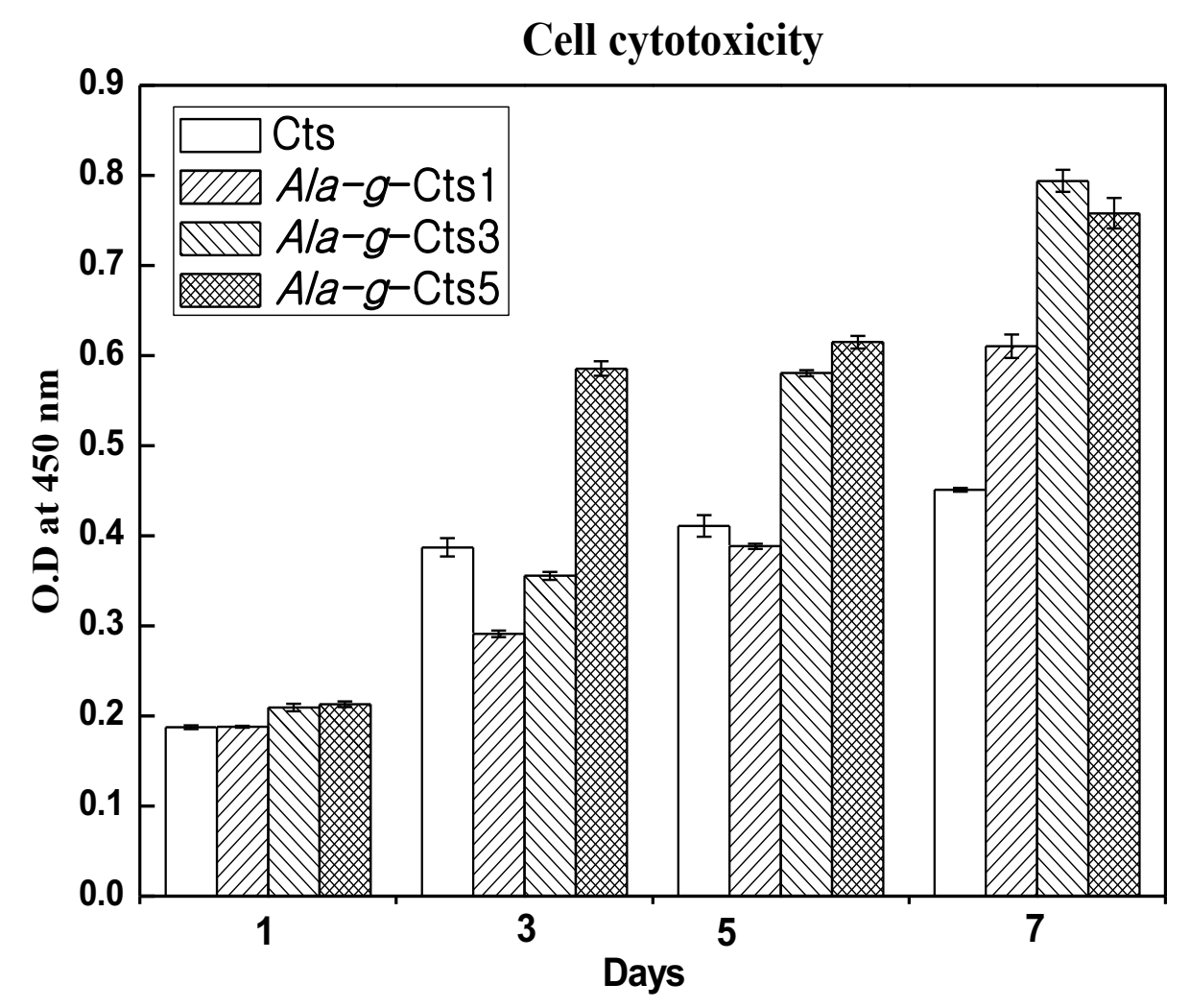

Figure12. Cell viability and proliferation results obtained using the CCK-8 test. For the control, the same amount of cells was seeded on 24 culture well plates. Cells were kept in culture for 1, 3, 5 and 7 days on Cts and crosslinked Ala-g-Cts films. 
Table 1. Solubility of Ala-g-Cts copolymers

\begin{tabular}{|c|c|c|c|c|c|c|c|c|c|}
\hline & $\mathrm{CHCl}_{3}$ & EA & THF & DMSO & DMF & Methanol & Ethanol & DW & PBS \\
\hline Ala-g-Cts1 & $\mathrm{x}$ & $\mathrm{x}$ & $\mathrm{x}$ & ( & $\bigcirc$ & $\mathrm{x}$ & $\mathrm{x}$ & $\bigcirc$ & $\circ$ \\
\hline Ala-g-Cts3 & $\mathrm{x}$ & $\mathrm{x}$ & $\Delta$ & ( & $\bigcirc$ & $\Delta$ & $\mathrm{x}$ & $\bigcirc$ & ( \\
\hline Ala-g-Cts5 & $\Delta$ & $\mathrm{x}$ & $\boldsymbol{\Delta}$ & ( & $\bigcirc$ & $\boldsymbol{\Delta}$ & $\Delta$ & $\bigcirc$ & ( \\
\hline
\end{tabular}

(○): completely soluble, $\circ$ : soluble (60-90\%), $\boldsymbol{\Delta}$ : soluble (40-60\%), $\Delta$ : slightely soluble (10$30 \%)$, x: insoluble $(<10 \%)$

EA: ethylacetate; THF: tetrahydrofuran; DMSO: dimethylsulfoxide; DMF: $N, N-$ dimethylformamide; DW: distilled water; PBS: phosphate buffer solution 